\title{
Avaliação do Tempo Atribuído à Travessia de Peões: Contributo para uma Lisboa Mais Inclusiva
}

\section{Assessment of Time Allocated to Pedestrian Crossing: A Contribution for a More Inclusive Lisbon}

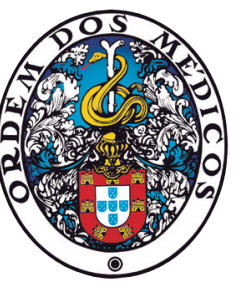

\author{
Sílvia BOAVENTURA ${ }^{1}$, Jorge RODRIGUES ${ }^{1}$, Teresa PLANCHA ${ }^{1}$, Mariana MARTINS ${ }^{1}$, Marta SILVA ${ }^{1}$, \\ Vitor Brás da SILVA ${ }^{1}$, Luís HORTA ${ }^{1}$, Pedro Soares BRANCO ${ }^{1}$ \\ Acta Med Port 2020 Jun;33(6):401-406 - https://doi.org/10.20344/amp.12527
}

\section{RESUMO}

Introdução: Com o envelhecimento progressivo da população portuguesa, é fundamental que as condições de acessibilidade e segurança na via pública estejam adaptadas a este grupo etário. O objectivo deste estudo foi avaliar se o tempo atribuído à travessia de peões nas passadeiras semaforizadas entre o Hospital de Curry Cabral e os transportes públicos locais é suficiente para permitir a travessia dos idosos em segurança.

Material e Métodos: Foram avaliados 100 doentes seguidos em consulta externa no Serviço de Medicina Física e de Reabilitação. Todos responderam a um questionário, à escala de confiança no equilíbrio específica da atividade e executaram o teste de marcha de 10 metros. Foram analisadas todas as passadeiras semaforizadas dos percursos de marcha entre o hospital e os transportes públicos locais, num total de 26 e calculada a velocidade de marcha necessária para realizar a travessia das passadeiras em segurança.

Resultados: A média de idade dos doentes foi de 75 anos, sendo a maioria do género feminino (73\%). Concluímos que todos os doentes conseguem atravessar em segurança 17 (65\%) passadeiras, representando as restantes nove (35\%) um obstáculo para a nossa amostra.

Discussão: Se o valor de velocidade de marcha nas passadeiras estipulado na legislação para os cidadãos com mobilidade condicionada fosse devidamente aplicado, $99 \%$ da amostra teria conseguido atravessar as passadeiras em segurança.

Conclusão: É fundamental que o valor de velocidade de marcha nas passadeiras estipulado na legislação seja aplicado, pois o seu incumprimento coloca em risco os utentes idosos do Hospital de Curry Cabral, aumentando a probabilidade de acidentes e o sentimento de insegurança na via pública.

Palavras-chave: Acidentes de Trânsito/prevenção e controlo; Idoso; Marcha; Pedestres; Portugal; Prevenção de Acidentes

\section{ABSTRACT}

Introduction: With progressive ageing of the Portuguese population, it is paramount that the conditions of outdoor accessibility and safety are adapted to this age group. The aim of this study was to assess whether the time allocated to pedestrian crossing in the crosswalks with pedestrian crossing lights between Curry Cabral Hospital and local public transport is enough to allow safe passage of the elderly.

Material and Methods: We evaluated 100 ambulatory care patients from the Physical Medicine and Rehabilitation department. All of them answered a questionnaire, the Activities-Specific Balance Confidence Scale (Portuguese version) and performed a 10-meter walk test. All crosswalks with pedestrian crossing lights between the hospital and local public transport were analyzed, in a total of 26 , and the gait speed required to perform a safe crossing was calculated.

Results: Mean age of patients was 75 years and the majority $(73 \%)$ were female. The study showed that all patients could safely cross $17(65 \%)$ crosswalks. The nine remaining crosswalks (35\%) represented an obstacle to our sample.

Discussion: If the required gait speed as currently set in legislation for the disabled was implemented, $99 \%$ of the patients would have been able to cross the crosswalks safely.

Conclusion: It is essential to apply the gait speed set in legislation, since non-compliance endangers elderly patients in Curry Cabral Hospital, increasing the likelihood of accidents and the feeling of insecurity on the streets.

Keywords: Accident Prevention; Accidents, Traffic/prevention \& control; Aged; Pedestrians; Portugal; Walking

\section{INTRODUÇÃO}

Dado o envelhecimento progressivo da população portuguesa (com um aumento da população idosa na região de Lisboa de 15,4\% em 2001 para 18,2\% em 2011), ${ }^{1}$ torna-se imperativo assegurar que as condições de acessibilidade e segurança na via pública se encontram adequadas a esta faixa etária. Com o processo natural de envelhecimento, algumas capacidades físicas e psicológicas tendem a diminuir. Os reflexos, as capacidades visuais, auditivas, de raciocínio, de perceção, de atenção, de concentração e de mobilidade vão ficando, progressivamente, mais limitadas. ${ }^{2}$ Este processo acarreta a diminuição da capacidade de previsão e antecipação do risco e o aumento do tempo de reacção, muitas vezes menosprezados pelos condutores. ${ }^{3}$ Segundo dados da PORDATA (base de dados Portugal Contemporâneo), o número de atropelamentos diminuiu consideravelmente na área metropolitana de Lisboa nos últimos anos (3963 em 1996 para 2005 em 2006), apesar de continuar a haver quase tantos atropelamentos nesta área como em todo o território Norte de Portugal (2005 na área metropolitana de Lisboa e 2124 no território Norte de Portugal), sendo os idosos um dos grupos etários em maior risco. ${ }^{4} \mathrm{~A}$ velocidade de marcha média do peão varia

\footnotetext{
1. Unidade Funcional Músculo-esquelética. Serviço de Medicina Física e de Reabilitação. Hospital de Curry Cabral. Centro Hospitalar Universitário de Lisboa Central. Lisboa.
} Portugal.

$\square$ Autor correspondente: Sílvia Boaventura. silviaboaventurab@gmail.com

Recebido: 08 de julho de 2019 - Aceite: 30 de outubro de 2019 | Copyright @ Ordem dos Médicos 2020 
entre os vários países. Segundo o Highway Capacity Manual (HCM 2010), a velocidade de marcha média do peão situa-se entre $1,0 \mathrm{~m} / \mathrm{s}$ e $1,2 \mathrm{~m} / \mathrm{s} .{ }^{5}$ Segundo a legislação portuguesa destinada aos cidadãos de mobilidade condicionada (DL 163/2006), o sinal verde de travessia de peões deve estar aberto o tempo suficiente para permitir a travessia dos peões a uma velocidade de 0,4 m/s, embora este valor seja de difícil aplicação prática. Promover a deslocação pedonal do idoso na cidade é benéfico para a saúde e estimula a interacção social. ${ }^{6}$ Todos os factores que prejudiquem essa actividade condicionam perda de autonomia e da qualidade de vida. O objectivo deste estudo foi avaliar se o tempo atribuído à travessia de peões nas passadeiras semaforizadas entre o Hospital de Curry Cabral (HCC) e os transportes públicos locais é suficiente para permitir a travessia em segurança dos idosos seguidos em consulta de Medicina Física e de Reabilitação (MFR).

\section{MATERIAL E MÉTODOS}

\section{Participantes}

Foram recrutados 100 doentes seguidos na consulta externa de MFR do HCC - Centro Hospitalar Universitário de Lisboa Central (CHULC) e obtido o respectivo consentimento informado antes de integrarem o estudo. Foram incluídos participantes com idade igual ou superior a 65 anos, com cidadania portuguesa, residentes na área metropolitana de Lisboa, seguidos em consulta externa de MFR do HCC, com capacidade de realizar marcha de forma autónoma com ou sem auxiliar de marcha e de deslocar-se 10 metros sem interrupções. Foram excluídos os participantes com doença cardíaca e/ou respiratória aguda ou crónica agudizada.

\section{Procedimentos}

Questionários: os participantes responderam a um questionário sobre a sua identificação, antecedentes pes- soais, medicação habitual, mobilidade na comunidade e percepção de condições de acessibilidade e segurança nas passadeiras. As questões eram de escolha múltipla e foram elaboradas pelos autores do estudo. Foram ainda avaliados na escala de confiança no equilíbrio específica da actividade (CEEA), versão validada para Portugal da Escala ABC (Activities-Specific Balance Confidence Scale). ${ }^{7}$

Testes aplicados: A velocidade de marcha foi avaliada através do teste de marcha de 10 metros. O teste foi realizado no interior do HCC, no exterior do edifício da consulta de MFR, em piso de gravilha sem inclinação, num percurso com 14 metros de comprimento (dois metros de aceleração e dois metros de desaceleração). O tempo necessário para percorrer os 10 metros intermediários foi cronometrado. Foram utilizadas marcas previamente pintadas no solo para assinalar o início e final do trajeto. Os participantes foram convidados a realizar o teste de marcha de 10 metros em duas condições diferentes: 1) velocidade de marcha habitual - solicitou-se ao doente que caminhasse à sua velocidade confortável e habitual; 2 ) velocidade de marcha máxima - o doente recebeu indicação para caminhar o mais rápido possível, com segurança. Os doentes realizaram uma vez o teste em cada uma das condições. O tempo necessário para percorrer os 10 metros foi registrado e, posteriormente, utilizado para calcular a velocidade de marcha em cada condição.

\section{Passadeiras (para peões)}

Foram analisadas todas as passadeiras semaforizadas dos percursos de marcha dos doentes do serviço de MFR do HCC para acesso aos transportes públicos locais. Foram tidos em consideração os acessos a partir das três entradas do HCC: entrada pelo portão da Rua da Beneficência, entrada pelo portão em frente ao Hotel Zurique e entrada pelo portão em frente ao Hotel Holiday Inn. Foram estudados os percursos entre as três entradas do HCC e os

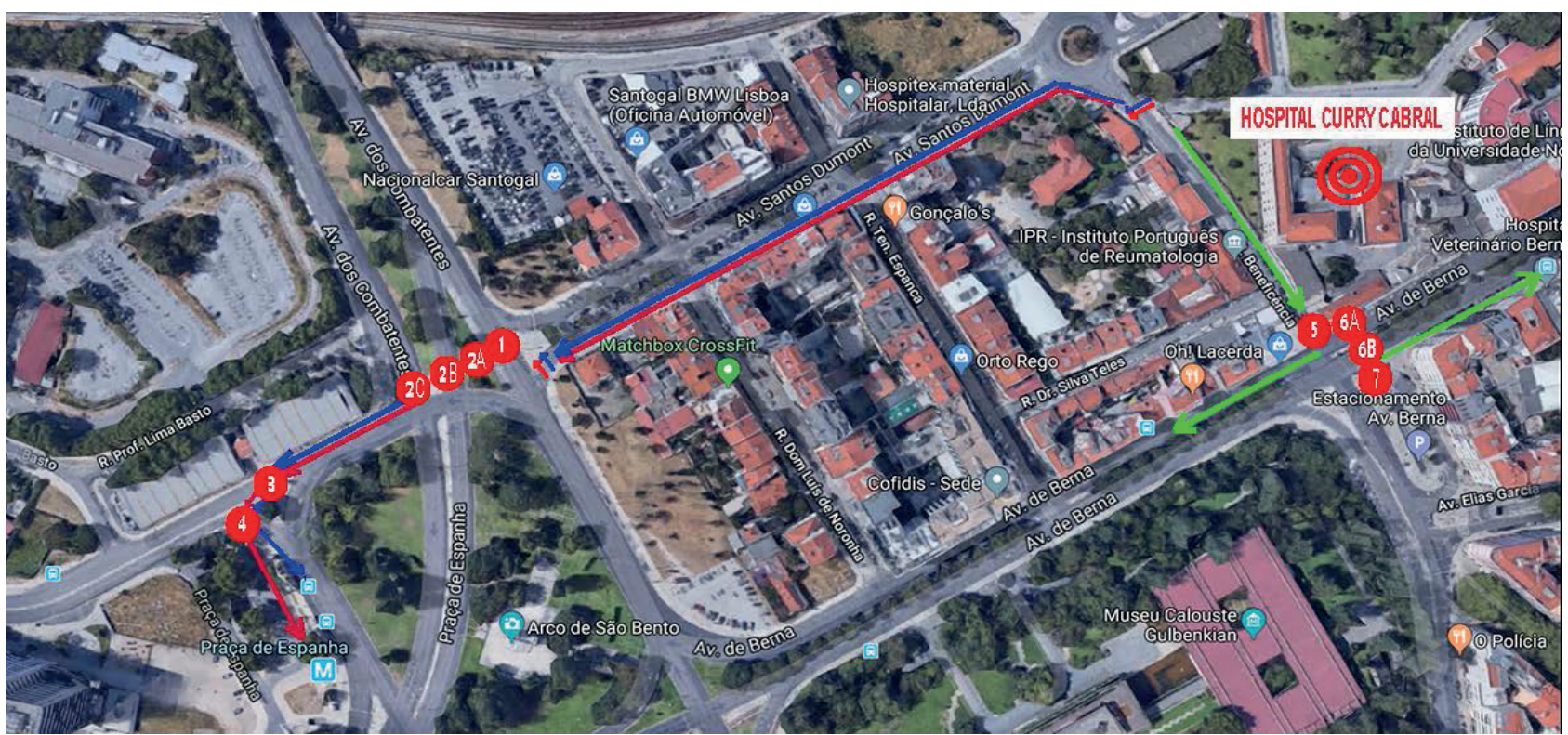

Figura 1 - Acesso pelo portão da Rua da Beneficência Map data: Google, DigitalGlobe. 
transportes públicos locais, totalizando nove percursos de marcha, nomeadamente:

- Acesso pelo portão da Rua da Beneficência: ligação ao metropolitano (estação Praça de Espanha); ligação aos autocarros da Praça de Espanha; ligação aos autocarros da Avenida de Berna (três percursos);

- Acesso pelo portão em frente ao Hotel Zurique: ligação ao comboio (estação de Entrecampos); ligação ao metropolitano (estação Campo Pequeno); ligação aos autocarros da Avenida da República (três percursos);

- Acesso pelo portão em frente ao Hotel Holiday Inn: ligação ao metropolitano (estação Campo Pequeno), ligação aos autocarros da Avenida da República; ligação aos autocarros da Avenida de Berna (três percursos).

Nas Fig.s 1, 2 e 3 encontram-se numeradas as passa- deiras semaforizadas e identificados os percursos de marcha através de setas.

Foi medido o comprimento das passadeiras utilizando uma fita métrica e cronometrado o tempo de abertura dos semáforos. Todos os tempos de abertura dos semáforos foram o resultado, no mínimo, de quatro avaliações realizadas ao longo de diversos dias, em momentos diferentes do dia, sendo uma delas realizada num sábado. Estes dados foram posteriormente utilizados para calcular a velocidade de marcha necessária para realizar a travessia da passadeira em segurança.

\section{Análise dos dados}

Os dados foram analisados com recurso ao programa informático Microsoft Excel. Foi feita uma análise descritiva

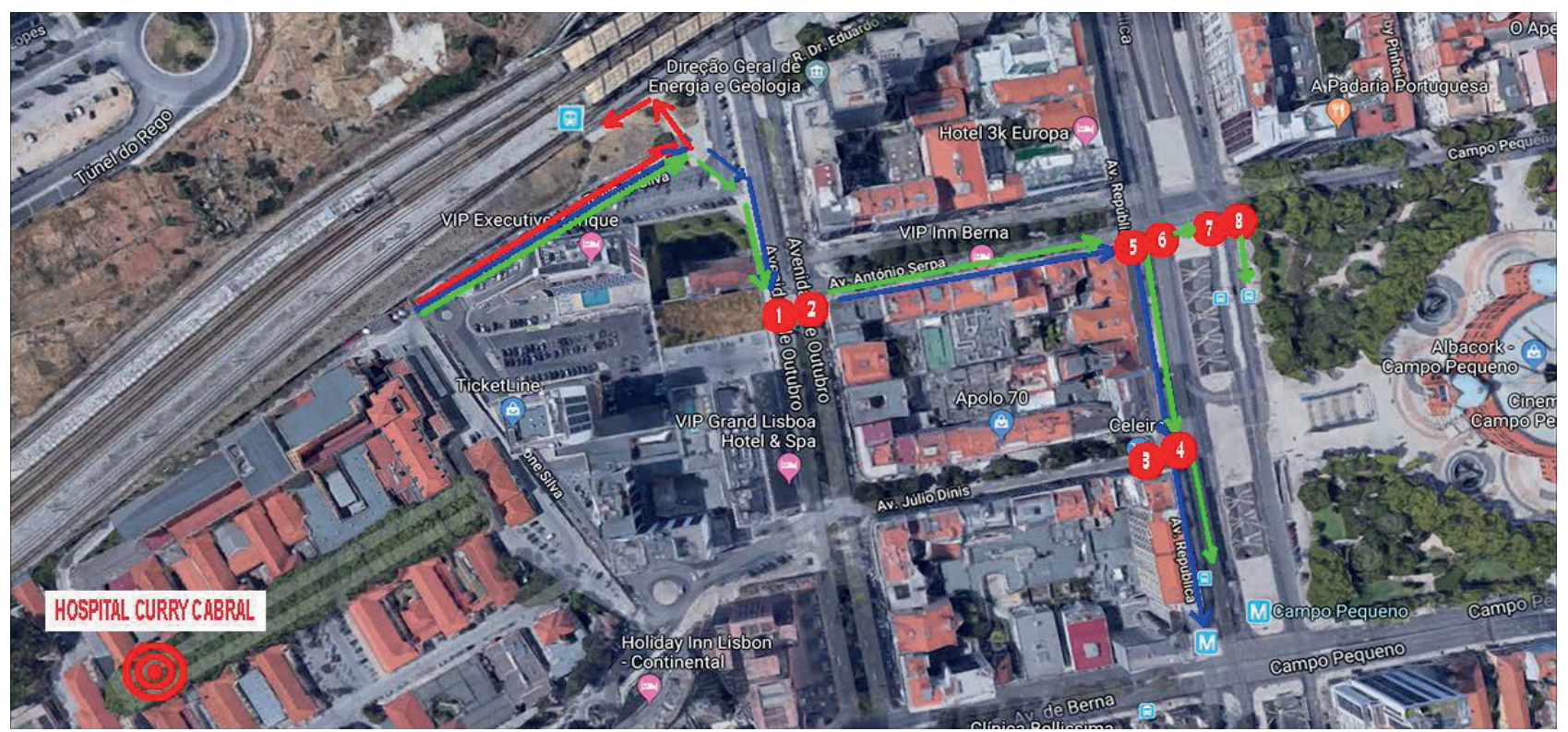

Figura 2 - Acesso pelo portão em frente ao Hotel Zurique. Map data: Google, DigitalGlobe.

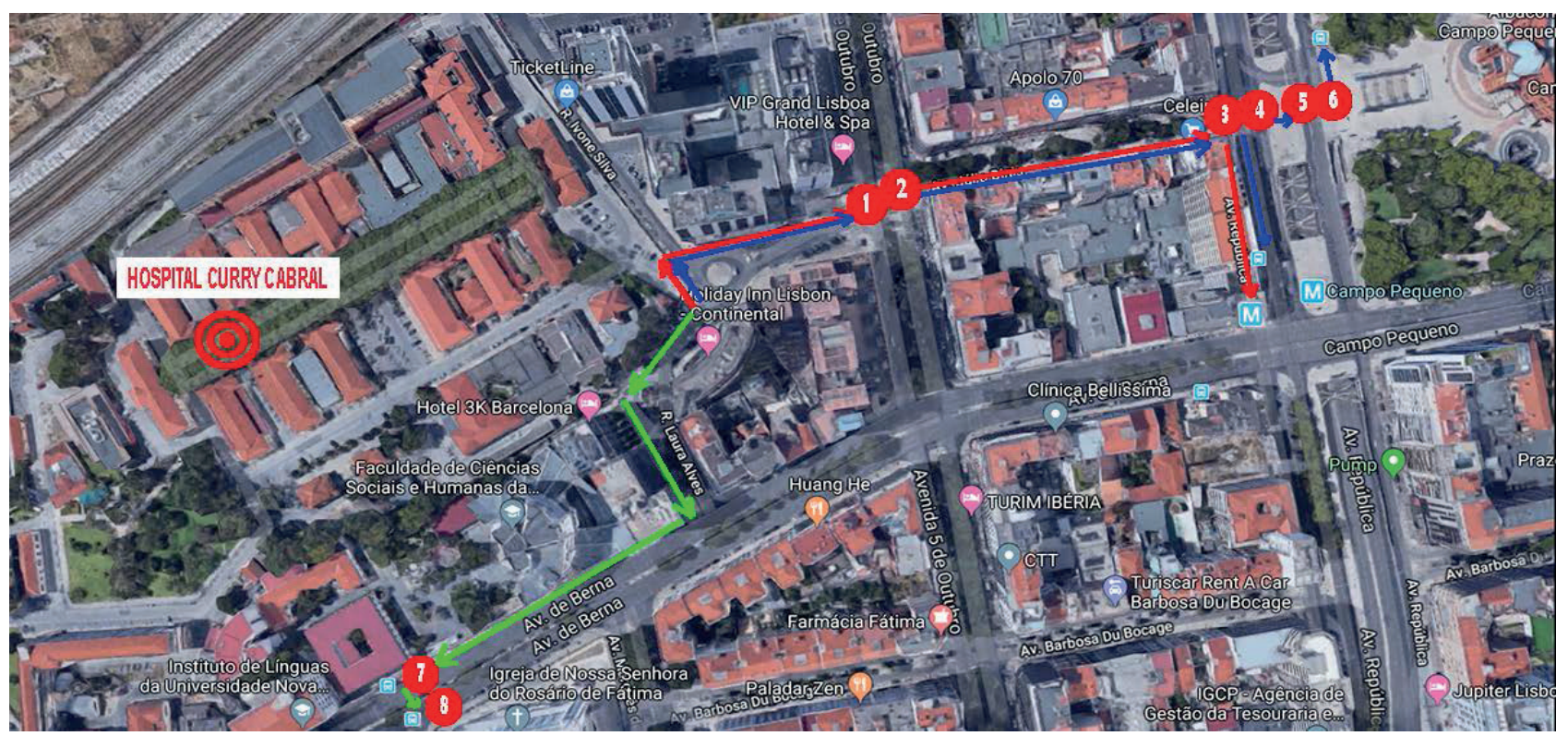

Figura 3 - Acesso pelo portão em frente ao Hotel Holiday Inn.

Map data: Google, DigitalGlobe. 
Tabela 1 - Estatística descritiva da amostra de doentes $(n=100)$

\begin{tabular}{|c|c|}
\hline \multicolumn{2}{|c|}{ Estatística descritiva da amostra de doentes } \\
\hline Idade (média \pm DP) & $75 \pm 6,32$ \\
\hline Género (feminino/masculino), \% (n) & $73 \%(73) / 27 \%(27)$ \\
\hline Auxiliar de marcha, \% (n) & $29 \%(29)$ \\
\hline Ortótese oftalmológica, \% (n) & $90 \%(90)$ \\
\hline № doenças crónicas (média $\pm \mathrm{DP}$ ) & $3 \pm 1,73$ \\
\hline $\mathrm{N}^{\circ}$ medicamentos (média $\pm \mathrm{DP}$ ) & $4 \pm 1,53$ \\
\hline CEEA (média \pm DP) & $934 \pm 378,9$ \\
\hline Velocidade normal (m/s) (média $\pm \mathrm{DP})$ & $0,81 \pm 5,22$ \\
\hline Velocidade máxima (m/s) (média \pm DP) & $0,95 \pm 4,64$ \\
\hline
\end{tabular}

DP: desvio-padrão dos participantes no estudo e das características das passadeiras.

\section{RESULTADOS}

\section{Caracterização dos doentes}

Foi avaliado um total de 100 doentes, cujas características são apresentados na Tabela 1. A média de idade dos doentes foi de 75 anos, sendo a maioria do género feminino (73\%). Vinte e nove utilizavam auxiliar de marcha: bengala (7), uma canadiana (17) ou duas canadianas (5). A escala CEEA procura caracterizar o nível de confiança no desempenho de 16 actividades de vida diária, possibilitando um resultado total entre 0 (mínimo) e 1600 (máximo). Considera-se o valor de 700 como ponto de corte para elevado risco de queda e o valor de 800 como ponto de corte para mobilidade normal. ${ }^{8} \mathrm{O}$ valor médio na nossa amostra foi de

Tabela 2 - Características das passadeiras

\begin{tabular}{|c|c|c|c|}
\hline \multicolumn{4}{|c|}{ Monitorização dos Semáforos } \\
\hline Locais & Passadeira & $\begin{array}{l}\text { Distância } \\
\text { (metros) }\end{array}$ & $\begin{array}{l}\text { Velocidade }(\mathrm{m} / \mathrm{s}) \\
\quad(\text { média } \pm \mathrm{DP})\end{array}$ \\
\hline \multicolumn{4}{|l|}{ Acesso pelo portão da Rua da Beneficência (1) } \\
\hline Av. Combatentes $1^{\mathrm{a}}$ travessia & 1 & 16,95 & $2,17 \pm 0,38$ \\
\hline Av. Combatentes $2^{\mathrm{a}}$ travessia & $2 \mathrm{~A}$ & 10,70 & $0,19 \pm 0,09$ \\
\hline Av. Combatentes $2^{\mathrm{a}}$ travessia & $2 \mathrm{~B}$ & 7,05 & $0,13 \pm 0,09$ \\
\hline Av. Combatentes $2^{\mathrm{a}}$ travessia & $2 \mathrm{C}$ & 11,20 & $0,20 \pm 0,09$ \\
\hline Av. Bordalo Pinheiro $1^{a}$ travessia & 3 & 7,80 & $1,02 \pm 0,09$ \\
\hline Av. Bordalo Pinheiro $2^{a}$ travessia & 4 & 8,40 & $0,14 \pm 0,02$ \\
\hline Rua da Beneficência & 5 & 9,85 & $0,29 \pm 0,05$ \\
\hline Av. de Berna (Beneficência) & $6 \mathrm{~A}$ & 9,35 & $0,29 \pm 0,02$ \\
\hline Av. de Berna (Beneficência) & $6 \mathrm{~B}$ & 12,30 & $0,32 \pm 0,02$ \\
\hline Av. de Berna (Lateral) & 7 & 5,00 & $0,07 \pm 0,01$ \\
\hline \multicolumn{4}{|c|}{ Acesso pelo portão em frente ao Hotel Zurique (2) } \\
\hline Av. 5 de Outubro (António Serpa) $1^{a}$ travessia & 1 & 6,10 & $0,57 \pm 0,04$ \\
\hline Av. 5 de Outubro (António Serpa) $2^{a}$ travessia & 2 & 7,75 & $0,16 \pm 0,01$ \\
\hline Av. Júlio Dinis (Av. da República) & 3 & 3,65 & $0,06 \pm 0,01$ \\
\hline Av. da República (acesso placa lateral) & 4 & 3,00 & $0,11 \pm 0,04$ \\
\hline Av. da República (António Serpa) & 5 & 3,00 & $0,09 \pm 0,21$ \\
\hline Av. da República (António Serpa) & 6 & 10,90 & $0,35 \pm 0,21$ \\
\hline Av. da República (António Serpa) & 7 & 4,05 & $0,13 \pm 0,21$ \\
\hline Av. da República (António Serpa) & 8 & 6,50 & $0,21 \pm 0,21$ \\
\hline \multicolumn{4}{|c|}{ Acesso pelo portão em frente ao Hotel Holiday Inn (3) } \\
\hline Av. 5 de Outubro (Júlio Dinis) $1^{\text {a }}$ travessia & 1 & 6,65 & $0,61 \pm 0,06$ \\
\hline Av. 5 de Outubro (Júlio Dinis) $2^{a}$ travessia & 2 & 7,30 & $0,86 \pm 0,11$ \\
\hline Av. Júlio Dinis (Av. da República) & 3 & 3,65 & $0,06 \pm 0,01$ \\
\hline Av. da República (acesso placa lateral) & 4 & 3,00 & $0,11 \pm 0,04$ \\
\hline Av. da República (Júlio Dinis) $2^{a}$ travessia & 5 & 10,90 & $1,00 \pm 0,06$ \\
\hline Av. da República (Júlio Dinis) $3^{a}$ travessia & 6 & 13,90 & $0,63 \pm 0$ \\
\hline Av. de Berna (Faculdade) $1^{\text {a }}$ travessia & 7 & 9,40 & $0,53 \pm 0,07$ \\
\hline Av. de Berna (Faculdade) $2^{a}$ travessia & 8 & 9,70 & $0,49 \pm 0,15$ \\
\hline
\end{tabular}

(1) Passadeiras identificadas na Fig. 1; (2) Passadeiras identificadas na Fig. 2; (3) Passadeiras identificadas na Fig. 3

DP: desvio-padrão 
Tabela 3 - Percentagens de doentes que conseguem atravessar as nove passadeiras que exigem uma velocidade de travessia superior a $0,4 \mathrm{~m} / \mathrm{s}$

\begin{tabular}{cccc}
\hline Passadeira & $\begin{array}{c}\text { Velocidade }(\mathrm{m} / \mathbf{s}) \\
\text { (média) }\end{array}$ & \multicolumn{2}{c}{ Percentagem } \\
Veloc N. & Veloc Máx. \\
\hline $1(1)$ & 2,17 & $0 \%$ & $0 \%$ \\
$3(1)$ & 1,02 & $46 \%$ & $60 \%$ \\
$5(3)$ & 1 & $49 \%$ & $62 \%$ \\
$2(3)$ & 0,86 & $60 \%$ & $75 \%$ \\
$6(3)$ & 0,63 & $84 \%$ & $91 \%$ \\
$1(3)$ & 0,61 & $85 \%$ & $91 \%$ \\
$1(2)$ & 0,57 & $88 \%$ & $92 \%$ \\
$7(3)$ & 0,53 & $91 \%$ & $94 \%$ \\
$8(3)$ & 0,49 & $92 \%$ & $97 \%$ \\
\hline
\end{tabular}

(1) Passadeiras identificadas na Fig. 1; (2) Passadeiras identificadas na Fig. 2; (3) Passadeiras identificadas na Fig. 3.

Veloc N.: velocidade normal; Veloc Máx: velocidade máxima

934; contudo, $31 \%$ dos doentes apresentou um valor $<700$ (elevado risco de queda). A velocidade média de marcha habitual foi de $0,81 \mathrm{~m} / \mathrm{s}$ e a velocidade média de marcha máxima foi de $0,95 \mathrm{~m} / \mathrm{s}$. Do total de 100 doentes da amostra, verificou-se uma velocidade de marcha inferior a 0,4 $\mathrm{m} / \mathrm{s}$ em apenas dois doentes, quando em marcha normal, e em apenas um doente, quando em marcha máxima. No questionário sobre mobilidade na comunidade e percepção de condições de acessibilidade e segurança nas passadeiras, $74 \%$ dos doentes assinalou sair de casa cinco ou mais vezes por semana, $19 \%$ entre três a quatro vezes por semana e $7 \%$ entre uma a duas vezes por semana. A maioria dos doentes (88\%) afirmou necessitar de atravessar passadeiras semaforizadas nos seus percursos na área metropolitana de Lisboa. Desses doentes, 31 (35\%) consideraram o tempo atribuído à travessia dos peões insuficiente para atravessar a passadeira em segurança; contudo, apenas sete desses doentes reportaram que isso os desencorajava de deambular na via pública. Em relação ao transporte que utilizam para se deslocar ao HCC, 26\% utilizam transporte próprio (conduzido pelo próprio ou por terceiros), $65 \%$ transporte público (41 autocarro, quatro metro, seis comboio, nove táxi e cinco uma combinação de dois transportes), $5 \%$ transporte institucional (sobretudo transporte da junta de freguesia) e $4 \%$ deslocavam-se a pé.

\section{Caracterização das passadeiras}

Um total de 26 passadeiras foram analisadas neste estudo, estando descrito na Tabela 2 a sua localização, comprimento e velocidade de marcha necessária para realizar a travessia da passadeira enquanto o semáforo para peões se encontra verde.

Analisando esses valores, verificámos que nove (35\%) passadeiras exigiam uma velocidade de marcha superior a $0,4 \mathrm{~m} / \mathrm{s}$ (valor máximo definido na legislação portuguesa destinada aos cidadãos de mobilidade condicionada para travessia de passadeiras). ${ }^{9}$

\section{Valores dos doentes versus Valores das passadeiras}

Analisando a velocidade de marcha (normal e máxima) da nossa amostra e comparando com a velocidade de marcha necessária para atravessar cada uma das 26 passadeiras em segurança, verificámos que todos os doentes conseguiam atravessar em segurança 17 (65\%) passadeiras, representando as restantes nove (35\%) um obstáculo para os doentes da nossa amostra. Na Tabela 3 encontram-se identificadas estas nove passadeiras, a velocidade necessária para as atravessar em segurança e a percentagem de doentes com capacidade para as atravessar.

\section{DISCUSSÃO}

O objectivo deste estudo foi avaliar se o tempo atribuído à travessia de peões nas passadeiras semaforizadas entre o HCC e os transportes públicos locais é suficiente para permitir a travessia em segurança dos idosos seguidos em consulta de MFR. Os resultados sugerem que, caso o valor de velocidade de marcha necessário para atravessar as passadeiras estipulado na legislação para os cidadãos com mobilidade condicionada fosse respeitado, 99\% da nossa amostra teria conseguido atravessar as passadeiras em segurança. Na realidade, contudo, verifica-se que mais de um terço das passadeiras em redor do HCC não cumprem este valor, exigindo velocidades de marcha superiores a $0,4 \mathrm{~m} / \mathrm{s}$. O caso mais flagrante é uma das passadeiras, situada na Avenida dos Combatentes, que exige uma velocidade de marcha mínima de $2,17 \mathrm{~m} / \mathrm{s}$ (mais de cinco vezes superior à velocidade definida na legislação para cidadãos de mobilidade condicionada), sendo esta velocidade inadequada para pessoas que, devido à sua idade ou patologia, não consigam andar em marcha acelerada. Dos nove percursos de marcha investigados, apenas três não têm pontos de dificuldade na travessia: um porque não exige a travessia de passadeiras semaforizadas e dois porque não possuem travessias que exijam velocidades de marcha superiores a $0,4 \mathrm{~m} / \mathrm{s}$. Importa referir que, na saída do HCC em frente ao hotel Holiday Inn, não existem passadeiras para atravessar a Rua Ivone Silva, o que representa um problema para os doentes que necessitem atravessar aquela via para aceder à Avenida 5 de Outubro. Todos os tempos de abertura dos semáforos analisados foram o resultado, no mínimo, de quatro avaliações realizadas ao longo de diversos dias, em momentos diferentes do dia. Embora se tenham verificado algumas oscilações dos tempos de abertura dos semáforos no decurso das diversas avaliações, em particular em alguns semáforos específicos, não parece haver uma relação destas oscilações com os diferentes fluxos de trânsito ou pelo facto de se tratar de um dia de semana ou de fim-de-semana. Os pontos onde existem maiores dificuldades na travessia também não parecem ser justificados por exigências relacionados com os fluxos de trânsito. Verificaram-se inclusivamente casos em que passadeiras localizadas sequencialmente no mesmo fluxo de trânsito apresentavam tempos de abertura dos semáforos muito diferentes, como por exemplo na Avenida 5 de Outubro. Este problema de acessibilidade 
apresenta particular relevância se tivermos em conta que mais de $2 / 3(69 \%)$ dos doentes analisados utilizam os transportes públicos ou deslocavam-se a pé para aceder ao HCC. De referir que esta situação afecta também os doentes do Instituto Português de Reumatologia, que utilizam alguns dos percursos de marcha avaliados. Uma das limitações deste estudo refere-se às condições em que foi analisada a velocidade de marcha da amostra. Atravessar uma passadeira semaforizada real exige especial atenção e capacidade de integração multissensorial, ${ }^{5}$ dado o indivíduo estar exposto a obstáculos (ex.: inclinações, desníveis, outros peões), ruídos, condições climatéricas, condições de trânsito e limite temporal indicado pelo semáforo. O medo de queda também pode diminuir a velocidade de marcha, e normalmente manifesta-se mais em actividades realizadas no exterior. Todos os factores supracitados estiveram ausentes da nossa simulação, o que pode ter contribuído para uma sobre-estimativa dos resultados da velocidade de marcha da amostra. ${ }^{10}$

\section{CONCLUSÃO}

O valor de velocidade de marcha nas passadeiras estipulado na legislação para os cidadãos com mobilidade condicionada é adequado. Contudo, mais de um terço das passadeiras em redor do HCC não cumprem esse valor. É fundamental que esta situação seja analisada e corrigida, porque condiciona a mobilidade na comunidade dos doentes e coloca-os em risco, aumentando a probabilidade de acidentes e o sentimento de insegurança na via pública.

\section{PROTECÇÃO DE PESSOAS E ANIMAIS}

Os autores declaram que o projecto foi aprovado pela Comissão de Ética do CHULC e está de acordo com a Declaração de Helsínquia da Associação Médica Mundial.

\section{CONFIDENCIALIDADE DOS DADOS}

Os autores declaram ter seguido os protocolos do seu centro de trabalho acerca da publicação de dados.

\section{CONFLITO DE INTERESSES}

Os autores declaram não ter nenhum conflito de interesses relativamente ao presente artigo.

\section{FONTES DE FINANCIAMENTO}

Não existiram fontes externas de financiamento para a realização deste artigo.

\section{REFERÊNCIAS}

1. Censos.ine.ptCensos.ine.pt. Lisboa: Censos 2011 Resultados Definitivos - Região Lisboa; 2011 [consultado 2018 jun 6]. Disponível em: https://censos.ine.pt/xportal/xmain?xpid=CENSOS\&xpgid=ine censos publicacao det\&menuBOUI=13707294\&contexto=pu\&PUBLIC ACOESpub_boui=156651739\&PUBLICACOESmodo=2\&selTab=tab1.

2. Bollard $\mathrm{E}$, Fleming $\mathrm{H}$. A study to investigate the walking speed of elderly adults with relation to pedestrian crossings. Physiother Theory Pract. 2013;29:142-9.

3. Autoridade Nacional de Segurança Rodoviária. Barcarena: Mais de 65 anos - Condução, Mobilidade e Segurança, 2014. [consultado 2019 jan 18]. Disponível em: http://www.ansr.pt/SegurancaRodoviaria/ Conselhos/Documents/MAIORES\%2065\%20ANOS\%20-\% 20 CONDU \% C 3 \% $87 \%$ C 3 \% $830 \% 20$ MOBILIDADE $\% 20$ E $\% 20$ SEGURAN\%C3\%87A.pdf.

4. Hoxie R, Rubenstein L. Are older pedestrians allowed enough time to cross intersections safely? J Am Geriatr Soc. 1994;42:241-4.

5. Onelcin P, Alver Y. The crossing speed and safety margin of pedestrians

at signalized intersections. Transp Res Proc. 2017;22:3-12.

6. Brown K, Heather M, Hanson M, Firmani F, Liu D, McAllister M, et al. Gait speed and variability for usual pace and pedestrian crossing conditions in older adults using the GAITRite Walkway. Gerontol Geriatr Med. 2015;2:1-8.

7. Branco P. Validação da versão portuguesa da "Activities-specific Balance Confidence Scale". Rev Soc Port Med Fis Reab. 2010:19:20-5.

8. Branco P. Avaliação e modificação do risco de queda em idosos com recurso à posturografia dinâmica computorizada, Lisboa; NMS-FCM Teses de Doutoramento2013. [consultado 2018 jul 2]. Disponível em: https://run.unl.pt/handle/10362/10526.

9. Decreto-Lei n. ${ }^{\circ}$ 163/2006. Diário da República, I Série, nº 152 (2006/08/08). p.5670-89.

10. Amosun S, Burgess T, Groeneveldt L, Hodgson T. Are elderly pedestrians allowed enough time at pedestrian crossings in Cape Town, South Africa? Physiother Theory Pract. 2007;23:325-32. 